\title{
Association of Cytotoxic T Lymphocyte Antigen-4 Gene Polymorphisms with Psoriasis Vulgaris: A Case-Control Study in Turkish Population
}

\author{
Hatice Gül Dursun $\mathbb{D}^{1}{ }^{1}$ Hüseyin Osman Yılmaz, ${ }^{1}$ Recep Dursun, ${ }^{2}$ and Sevsen Kulaksızoğlu ${ }^{3}$ \\ ${ }^{1}$ Department of Medical Biology, Meram Faculty of Medicine, Necmettin Erbakan University, 42080 Konya, Turkey \\ ${ }^{2}$ Department of Dermatology, Meram Faculty of Medicine, Necmettin Erbakan University, 42080 Konya, Turkey \\ ${ }^{3}$ Department of Clinical Biochemistry, School of Medicine, Baskent University, Konya, Turkey \\ Correspondence should be addressed to Hatice Gül Dursun; guldurakbasi@yahoo.com
}

Received 3 January 2018; Revised 6 March 2018; Accepted 14 March 2018; Published 23 April 2018

Academic Editor: Margarete D. Bagatini

Copyright (c) 2018 Hatice Gül Dursun et al. This is an open access article distributed under the Creative Commons Attribution License, which permits unrestricted use, distribution, and reproduction in any medium, provided the original work is properly cited.

\begin{abstract}
Psoriasis is a common, chronic, and autoimmune skin disease in which dysregulation of immune cells, particularly T cells, is thought to play an important role in the pathogenesis. Cytotoxic T lymphocyte antigen-4 (CTLA-4) expressed only on activated $\mathrm{T}$ cells is an immunoregulatory molecule and plays a role in the pathogenesis of autoimmune disorders. We aimed to determine whether CTLA-4 gene polymorphisms are associated with development and/or clinical features of psoriasis vulgaris (Pv). Genotyping of SNPs $(-318 \mathrm{C}>\mathrm{T},+49 \mathrm{~A}>\mathrm{G}$, and CT60A $>\mathrm{G})$ in CTLA-4 gene was performed using polymerase chain reactionrestriction fragment length polymorphism (PCR-RFLP) in $103 \mathrm{Pv}$ patients and 102 controls. No statistically significant associations were detected in any of the investigated genetic models for the $-318 \mathrm{C}>\mathrm{T}$ polymorphism. The genotype distributions of $+49 \mathrm{~A}>\mathrm{G}$ and $\mathrm{CT} 60 \mathrm{~A}>\mathrm{G}$ were associated with Pv development. In haplotype analysis, while frequency of CAA haplotype was significantly higher in the control group, frequencies of CGG and CAG haplotype were significantly higher among the patients. However, all of CTLA-4 polymorphisms and haplotypes do not have an effect on severity and onset age of Pv. In conclusion, the $+49 \mathrm{~A}>\mathrm{G}$ and CT60A $>\mathrm{G}$ polymorphisms may be risk factors for Pv development. Furthermore, CGG and CAG haplotypes may contribute to Pv development, while CAA haplotype may be protective against Pv.
\end{abstract}

\section{Introduction}

Psoriasis is a common inflammatory skin disease that affects approximately 125 million people globally [1]. The disease that exhibits a variable clinical presentation is characterized by lesions in the form of circular, red papules and plaques with a grey or silvery-white, dry scale. Psoriatic lesions are generally distributed symmetrically on the scalp, elbows, knees, lumbosacral area, and umbilicus $[2,3]$. In addition, nail disease and/or psoriatic arthritis, which can be very painful and deforming, may develop in many patients with psoriasis [2-5]. The incidence of psoriasis in women and men is almost equal [3]. Psoriasis is associated with several comorbidities, such as Chron's disease [6, 7], cardiovascular syndrome $[8,9]$, metabolic syndrome $[10-12]$, depression
[13], and cancer [14, 15]. The disease leads to a serious reduction in the quality of a patient's life, because it is linked with social stigmatization, pain, discomfort, physical disability, and psychological distress [2]. Recently, psoriasis has begun to be defined as a disease spectrum or systemic disease because of abovementioned concomitant comorbidities. As a result, it requires lifelong treatment [16]. Although the molecular pathogenesis of the disease is still poorly understood, it is generally agreed that psoriasis is triggered by some environmental factors such as stress, infections, trauma, and drugs with a genetic background [17]. The common view about the molecular pathogenesis of the disease is that alterations in the complex interactions between $\mathrm{T}$ lymphocytes, dendritic cells, macrophages, mast cells, neutrophils, keratinocytes, cytokines, and chemokines cause psoriasis, and this wise 
unbalanced immune response contributes to the psoriatic process $[18,19]$. Psoriasis has four major clinical phenotypes, which are distinguished by the morphological characteristics of their lesions: (i) psoriasis vulgaris, (ii) guttate psoriasis, (iii) pustular psoriasis, and (iv) erythrodermic psoriasis [20]. The most common of these clinical phenotypes is psoriasis vulgaris, responsible for $90 \%$ of all cases, and is also known as plaque psoriasis [3]. In this phenotype, the lesions are dry, sharply demarcated, oval/circular plaques and can be localized all over the body, but eventually affecting mostly the knees, elbows, lumbosacral area, intergluteal cleft, and scalp[20, 21].

Cytotoxic T lymphocyte antigen-4 (CTLA-4) is an important immunoregulatory molecule that plays a role in the maintenance of $\mathrm{T}$ cell homeostasis. In $\mathrm{T}$ cell-mediated immunological response, the interaction of $\mathrm{MHC}$ on antigen-presenting cell (APC) with CD28 on T cell is essential but not sufficient for $\mathrm{T}$ cell activation. However, the additional costimulatory factors and pathways are required for $\mathrm{T}$ cell activation $[22,23]$. One of the costimulatory pathways is B7- (CD80/86) CD28 [22]. CD28 expressed on antigen-presenting cells by naive T cells binds to B7 (CD80/ 86) initiates the proliferation, differentiation, and cytokine production in $\mathrm{T}$ cells. Binding of CTLA- 4 expressed by $\mathrm{T}$ cells to B7 presented on APC contributes to peripheral tolerance leading to the arrest of $\mathrm{T}$ cell cycle and termination of $\mathrm{T}$ cell activation [22, 24]. CTLA-4 acts as an inhibitor of autoimmunity, and the defects in the B7-CD28/CTLA-4 pathway may lower the threshold of autoreactive lymphocyte activation and which in turn may lead to the development of an autoimmune disease [25]. CTLA-4 molecule is encoded by the CTLA-4 gene (gene ID: 1493; OMIM*123890) located on chromosome 2p33 [26]. Several polymorphisms were identified in the CTLA-4 gene. The polymorphisms reducing the CTLA-4 expression or function may cause autoimmune clonal $\mathrm{T}$ cell proliferation and thus the development of autoimmune diseases [27]. In fact, some association studies indicated that there is an association between several CTLA-4 gene polymorphisms and various autoimmune diseases [28-48]. Recently, it has been shown that polymorphisms of many genes that are directly or indirectly related to the immune system and/or inflammation are associated with psoriasis. These include genes such as ADAM33 (a disintegrin and metalloprotease33) [49], TLR2 and TLR4 (toll-like receptor 2 and 4) [50], MCP-1 (monocyte chemoattractant protein-1) and RANTES (regulated upon activation normal $\mathrm{T}$ cell expressed and secreted) [51], TNF $\alpha$ (tumor necrosis factor alpha) [52], PON1 (paraoxonase) [53], IL-4 and IL-10 (interleukins) [54], HLA [55], VEGF (vascular endothelial growth factor) [56], and ERAP (endoplazmic reticulum aminopeptidase) [57]. However, there are a few studies establishing a possible relationship between CTLA-4 gene polymorphisms and psoriasis.

In the present study, we have conducted a research on three single-nucleotide polymorphisms (SNPs) in the CTLA-4 gene, because of its possible effects on expression level or function of the CTLA-4 molecule: $-318 \mathrm{C}>\mathrm{T}$ (in promoter), $+49 \mathrm{~A}>\mathrm{G}$ (in exon-1), and CT60A $>\mathrm{G}$ (in exon-4). With this hypothesis, our goal was (i) to investigate whether the CTLA-4 gene polymorphisms are related to the development of $\mathrm{Pv}$ (psoriasis vulgaris) and (ii) to detect whether the CTLA-4 gene polymorphisms have an impact on the clinical features of $P$. vulgaris such as onset age and severity. In the literature, there are few studies which observed the relationship between CTLA-4 gene polymorphisms and $\mathrm{Pv}$ [58-61]. Yet, there are no previous studies revealing a relationship between CTLA-4 genes $-318 \mathrm{C}>\mathrm{T},+49 \mathrm{~A}>\mathrm{G}$, and CT60A $>$ G SNPs and the development of Pv.

\section{Subjects and Methods}

2.1. Research Population. 103 unrelated Turkish Pv patients were selected for the experimental group, and 102 unrelated healthy Turkish people were selected for the control group. Psoriasis vulgaris patients (66 female/37 male; mean age \pm SD: $37.83 \pm 16.83$ ) were recruited from a dermatologic clinic. The patients with other chronic and autoimmune diseases or cancer were excluded from the study. The control group ( 58 female/44 male; mean age \pm SD: $37.23 \pm 16.77$ ) was formed with healthy individuals who did not have cancer, psoriasis, and other autoimmune diseases and did not have a family history of these diseases. The patients and control subjects were matched according to their gender and age. Severity of psoriasis was assessed with Psoriasis Area and Severity Index (PASI), ranging from 0 (no disease) to 72, with higher scores indicating the severity of disease [62]. To determine the association of CTLA-4 gene polymorphisms with the clinical features of $\mathrm{Pv}$, the patients were divided into two groups according to the severity of disease (PASI $<12$ group and $\mathrm{PASI} \geq 12$ group) and then assigned into two groups according to the onset of disease (early-onset group: $<40$ age and late-onset group: $\geq 40$ age) (Table 1 ).

This study was conducted in accordance with the Declaration of Helsinki principles and was approved by the Ethics Committee of Meram Medical Faculty (number 2010/138). Informed consent was obtained from all the participants before the study.

2.2. Genotyping. Peripheral blood sample was taken from each patient and control subject collected in tubes containing EDTA and stored at $-20^{\circ} \mathrm{C}$ before DNA isolation. Genomic DNA was extracted from the blood sample using the QIAamp DNA Blood Mini Kit (Qiagen, Hilden, Germany). Genotyping of the CTLA-4 gene -318C>T (rs5742909), $+49 \mathrm{~A}>\mathrm{G}(\mathrm{rs} 231775)$, and CT60A $>\mathrm{G}$ (rs3087243) was carried out by the polymerase chain reaction-restriction length polymorphism (PCR-RFLP) using MseII, BbvI, and NcoI enzymes (New England BioLabs, Hitchin, UK). PCR reactions were performed with mixtures consisting of $0.2 \mu \mathrm{g}$ genomic DNA, $5 \mu \mathrm{l}$ ammonium buffer, $4.5 \mu \mathrm{MgCl}_{2}, 20 \mathrm{pmol}$ of each primer, 5 unit Taq polymerase, and double-distilled $\mathrm{H}_{2} \mathrm{O}$ up to final volume of $50 \mu \mathrm{l}$. The primers were designed according to the complete CTLA-4 gene sequence derived from NCBI Sequence Viewer (http://www.ncbi.nlm.nig.gov/). PCR was carried out with denaturation at $95^{\circ} \mathrm{C}$ for 5 minutes, followed by 35 cycles of 45 seconds at $94^{\circ} \mathrm{C}, 45$ seconds at $55^{\circ} \mathrm{C}$, and 45 seconds at $72^{\circ} \mathrm{C}$ and finally 10 minutes at $72^{\circ} \mathrm{C}$. The PCR products were digested using $10 \mathrm{U}$ of MseII, 
TABLE 1: Characteristics of the study population.

\begin{tabular}{|c|c|c|c|c|c|}
\hline & \multicolumn{4}{|c|}{ Patients } & Control \\
\hline Total number $(n)$ & \multicolumn{4}{|c|}{103} & 102 \\
\hline Female/male $(n)$ & \multicolumn{4}{|c|}{$66 / 37$} & $58 / 44$ \\
\hline Age $($ mean \pm SD (year) $)$ & \multicolumn{4}{|c|}{$37.83 \pm 16.83$} & $37.23 \pm 16.77$ \\
\hline \multirow{4}{*}{ Other features } & \multicolumn{4}{|c|}{ With $P$. vulgaris } & Healthy \\
\hline & \multicolumn{4}{|c|}{ Unrelated } & Unrelated \\
\hline & \multicolumn{4}{|c|}{ Without cancer history } & Without cancer history \\
\hline & \multicolumn{4}{|c|}{ Without other autoimmune disorders and other chronic diseases } & \\
\hline \multirow{3}{*}{ Subgroups } & \multicolumn{2}{|c|}{ According to the age of onset } & \multicolumn{2}{|c|}{ According to the age of severity } & \\
\hline & Early $<40$ age $(n)$ & Late $\geq 40$ age $(n)$ & PASI $<12(n)$ & $\mathrm{PASI} \geq 12(n)$ & \\
\hline & 88 & 15 & 59 & 44 & \\
\hline
\end{tabular}

$6 \mathrm{U}$ of $\mathrm{Bbv \textrm {I }}$, and $10 \mathrm{U}$ of $\mathrm{NcoI}$ enzymes and then electrophoresed on $2.5 \%$ agarose gel, stained with ethidium bromide, and evaluated. The primers used for PCR, conditions for digestion, products of digestion, and genotypes determined according to the products of digestion are listed in Table 2.

2.3. Statistical Analysis. The SPSS 13.0 package programme was used for data analysis. Comparisons of the distributions of allele and genotype frequencies were performed by Pearson's chi-squared test. The deviation from the Hardy-Weinberg equilibrium was tested using chi-square analysis. To test the association between $\mathrm{Pv}$ and CTLA-4 polymorphisms, logistic regression analysis was performed according to five inheritance models (codominant 1, codominant 2, dominant, recessive, and log-additive). Odds ratios (OR), 95\% confidence intervals (CI), and $p$ values were determined using SNPStats (http://bioinfo.iconcologia.net/ index.php?module=Snpstats) and SPSS 13.0 program. The linkage disequilibrium (LD) blocks and haplotypes were estimated using Haploview version 4.2 (http://www.broadinstitu te.org/scientific-community/science/programs/medical-andpopulation-genetics/haploview). $p$ values less than 0.05 were considered significant.

\section{Results}

3.1. Genotype Analysis and Association of SNPs with Pv. Table 3 shows the genotype and allele frequencies of CTLA-4 polymorphisms $(-318 \mathrm{C}>\mathrm{T},+49 \mathrm{~A}>\mathrm{G}$, and CT60A $>\mathrm{G}$ ) in $\mathrm{Pv}$ patients and the control group. The genotype distributions of the examined SNPs were consistent with the Hardy-Weinberg equilibrium (HWE) (Table 3).

In multiple logistic regression analysis, $-318 \mathrm{C}>\mathrm{T}$ SNP was not associated with the development of $\operatorname{Pv}(p>0.05$ for all genetic models and $\mathrm{T}$ allele frequency). However, $+49 \mathrm{~A}>\mathrm{G}$ and CT60A $>\mathrm{G}$ SNPs were associated with Pv. The disease-related risk was observed in the codominant 1 model $(\mathrm{OR}=0.57, p=0.04)$, dominant model $(\mathrm{OR}=0.54, p=0.03)$, and $\log$-additive model $(\mathrm{OR}=0.62$ and $p=0.03)$ for $+49 \mathrm{~A}>\mathrm{G}$ and in the codominant 2 model $(\mathrm{OR}=0.29, p=0.004)$ and recessive model $(\mathrm{OR}=1.33, p=0.001)$ for $\mathrm{CT} 60$. In addition, $\mathrm{G}$ allele (minor allele) frequencies of both $+49 \mathrm{~A}>\mathrm{G}$ and
CT60A $>$ G SNPs were higher in the Pv patient $(31 \%$ for $+49 \mathrm{~A}>\mathrm{G}$ and $55 \%$ for $\mathrm{CT} 60 \mathrm{~A}>\mathrm{G}$ ) than in the control group $(21 \%$ for $+49 \mathrm{~A}>\mathrm{G}$ and $40 \%$ for $\mathrm{CT} 60 \mathrm{~A}>\mathrm{G})(\mathrm{OR}=0.59, p=$ 0.02 for $+49 \mathrm{~A}>\mathrm{G}$ and $\mathrm{OR}=0.54, p=0.002$ for $\mathrm{CT} 60 \mathrm{~A}>\mathrm{G})$.

3.2. Genotype Analysis and Association of SNPs with Clinical Features of $P v$. Tables 4 and 5 present the genotype and allele frequencies of CTLA-4 SNPs in clinical subgroups of Pv (onset age of disease and severity of disease). None of the examined SNPs showed no association with onset age and severity of $\mathrm{Pv}$ (for all genetic models). The genotype and allele frequencies of examined SNPs did not differ between the early group and late group (Table 4 ) and PASI $<12$ group and PASI $\geq 12$ group (Table 5). The results indicated that $-318 \mathrm{C}>\mathrm{T},+49 \mathrm{~A}>\mathrm{G}$, and CT60A $>\mathrm{G}$ SNPs have no effect on the onset age and severity of $\mathrm{Pv}$.

3.3. Linkage Disequilibrium and Haplotype Analysis. We estimated the linkage disequilibrium (LD) block by using Haploview version 4.2. The $\mathrm{LD}$ block was strongly made between $-318 \mathrm{C}>\mathrm{T}$ and $+49 \mathrm{~A}>\mathrm{G} \quad\left(D^{\prime}=0.999\right.$ and $\left.r^{2}=0.043\right)$, $-318 \mathrm{C}>\mathrm{T}$ and $\mathrm{CT} 60 \mathrm{~A}>\mathrm{G}\left(D^{\prime}=0.999\right.$ and $\left.r^{2}=0.141\right)$, and $+49 \mathrm{~A}>\mathrm{G}$ and $\mathrm{CT} 60 \mathrm{~A}>\mathrm{G}\left(D^{\prime}=1.000\right.$ and $\left.r^{2}=0.383\right)$. In haplotype analysis which was performed to investigate the association between the haplotypes of LD block SNPs and Pv, four major haplotypes were detected which are CAA, CGG, TAG, and CAG (Table 6). The frequencies of these haplotypes were $0.532,0.253,0.110$, and 0.103 , respectively. A significantly higher frequency of CAA haplotype was found in controls (0.603) than in $\mathrm{Pv}$ patients $(0.461, p=0.004)$. In contrast, significant increases in the frequencies of CGG and CAG haplotypes were observed in patients (0.306 and 0.146 , resp.) compared to healthy individuals in the control group ( 0.201 and 0.059 , resp.; $p=0.015$ and $p=0.004$ ). These results suggest that while the CAA haplotype may have a protective effect on the development of Pv, the CGG and CAG haplotypes may be associated with the development of $\mathrm{Pv}$. In haplotype analysis which was performed to investigate the association between the haplotypes and the clinical subgroups of $\mathrm{Pv}$, three major haplotypes were detected which are AA, GG, and AG (Table 7). The frequencies of these haplotypes were $0.461,0.306$, and 0.233 , respectively. Considering the onset age of $\mathrm{Pv}$, the frequencies of these haplotypes 
TABle 2: Primers, conditions for digestion, products of digestion, and genotypes according to products of digestion.

\begin{tabular}{|c|c|c|c|c|c|}
\hline SNP & Primers & Amplicon (bp) & $\mathrm{RE}$ & $\begin{array}{l}\text { Temperature and } \\
\text { duration of digestion }\end{array}$ & $\begin{array}{l}\text { Products of digestion (bp) } \\
\text { and genotypes }\end{array}$ \\
\hline$-318 \mathrm{C}>\mathrm{T}$ & $\begin{array}{l}\text { F: 5'-AAATGAATTGGACTGGATGGT-3' } \\
\text { R: } 3^{\prime} \text {-TTACGAGAAAGGAAGCCGTG-5' }\end{array}$ & 247 & MseII & $37^{\circ} \mathrm{C}$, overnight & $\begin{array}{c}\text { CC: } 247 \\
\text { CT: } 20,95,132,247 \\
\text { TT: } 20,95,132\end{array}$ \\
\hline$+49 \mathrm{~A}>\mathrm{G}$ & $\begin{array}{l}\text { F: } 5^{\prime} \text {-TTGCTCTACTTCCTGAAGACCTGAA-3' } \\
\text { R: } 3^{\prime} \text {-AAAGTCTCACTCACCTTTGCAGAAG-5' }\end{array}$ & 166 & $B b v \mathrm{I}$ & $37^{\circ} \mathrm{C}$, overnight & $\begin{array}{c}\text { AA: } 166 \\
\text { AG: } 76,90,166 \\
\text { GG: } 76,90 \\
\end{array}$ \\
\hline CT60 A>G & $\begin{array}{l}\text { F: } 5^{\prime} \text {-CAC CACTATTTGGGATATACC-3' } \\
\text { R: } 3^{\prime} \text {-AGGTCTATATTTCAGGAAGGC-5' }\end{array}$ & 216 & $\mathrm{NcoI}$ & $37^{\circ} \mathrm{C}$, overnight & $\begin{array}{c}\text { AA: } 20,196 \\
\text { AG: } 20,196,216 \\
\text { GG: } 216\end{array}$ \\
\hline
\end{tabular}

TABLe 3: Genotype and allele frequencies of CTLA-4 gene polymorphisms in Pv patients and control and the association of these polymorphisms with Pv.

\begin{tabular}{|c|c|c|c|c|c|c|c|c|}
\hline SNP & Genotype/allele & Cases $n(\%)$ & Controls $n(\%)$ & HWE $p$ (cases) & HWE $p$ (controls) & Model & OR $(95 \% \mathrm{CI})$ & $p$ \\
\hline rs5742909 & $\mathrm{CC}$ & $86(0.83)$ & $75(0.74)$ & 0.79 & 0.44 & Codominant 1 & $1.84(0.92-3.70)$ & 0.85 \\
\hline \multirow[t]{5}{*}{$(-318 \mathrm{C}>\mathrm{T})$} & $\mathrm{CT}$ & $16(0.16)$ & $26(0.25)$ & & & Codominant 2 & $1.08(0.07-17.89)$ & 0.22 \\
\hline & $\mathrm{TT}$ & $1(0.01)$ & $1(0.01)$ & & & Dominant & $1.80(0.91-3.56)$ & 0.09 \\
\hline & & & & & & Recessive & $0.95(0.06-15.67)$ & 0.97 \\
\hline & $\mathrm{C}$ & $188(0.91)$ & $176(0.86)$ & & & Log-additive & $1.67(0.88-3.17)$ & 0.11 \\
\hline & $\mathrm{T}$ & $18(0.09)$ & $28(0.14)$ & & & Minor allele & $1.66(0.88-3.11)$ & 0.11 \\
\hline rs231775 & AA & $51(0.50)$ & $66(0.65)$ & 0.53 & 0.31 & Codominant 1 & $0.57(0.31-1.04)$ & $0.04^{\mathrm{a}}$ \\
\hline \multirow[t]{5}{*}{$(+49 \mathrm{~A}>\mathrm{G})$} & $A G$ & $41(0.39)$ & $30(0.29)$ & & & Codominant 2 & $0.43(0.15-1.25)$ & 0.09 \\
\hline & GG & $11(0.11)$ & $6(0.06)$ & & & Dominant & $0.54(0.31-0.95)$ & $0.03^{\mathrm{a}}$ \\
\hline & & & & & & Recessive & $0.53(0.19-1.50)$ & 0.22 \\
\hline & A & $143(0.69)$ & $162(0.79)$ & & & Log-additive & $0.62(0.40-0.96)$ & $0.03^{\mathrm{a}}$ \\
\hline & G & $63(0.31)$ & $42(0.21)$ & & & Minor allele & $0.59(0.38-0.92)$ & $0.02^{\mathrm{a}}$ \\
\hline rs3087243 & AA & $25(0.24)$ & $36(0.35)$ & 0.11 & 0.65 & Codominant 1 & $0.81(0.42-1.55)$ & 0.06 \\
\hline \multirow[t]{5}{*}{$(\mathrm{CT} 60 \mathrm{~A}>\mathrm{G})$} & AG & $43(0.42)$ & $51(0.50)$ & & & Codominant 2 & $0.29(0.13-0.64)$ & $0.004^{\mathrm{a}}$ \\
\hline & GG & $35(0.34)$ & $15(0.15)$ & & & Dominant & $0.58(0.17-0.66)$ & 0.07 \\
\hline & & & & & & Recessive & $1.33(0.17-0.66)$ & $0.001^{\mathrm{a}}$ \\
\hline & A & $93(0.45)$ & $123(0.6)$ & & & Log-additive & $1.38(0.80-2.40)$ & 0.25 \\
\hline & G & $113(0.55)$ & $81(0.40)$ & & & Minor allele & $0.54(0.37-0.80)$ & $0.002^{\mathrm{a}}$ \\
\hline
\end{tabular}

SNP: single-nucleotide polymorphism; HWE: Hardy-Weinberg equilibrium; OR: odds ratio; CI: confidence interval. ${ }^{\text {a} S t a t i s t i c a l l y ~ s i g n i f i c a n t ~ v a l u e s ~}(p<0.05)$. Codominant 1: major allele homozygotes versus heterozygotes; codominant 2: major allele homozygotes versus minor allele homozygotes; dominant: major allele homozygotes versus heterozygotes + minor allele homozygotes; recessive: major allele homozygotes + heterozygotes versus minor allele homozygotes; log-additive: major allele homozygotes versus heterozygotes versus minor allele homozygotes.

did not differ between the early group and the late group ( $p=0.467, p=0.434$, and $p=0.243$, resp.). There was no significant difference between the PASI $<12$ group and the $\mathrm{PASI} \geq 12$ group with respect to the frequencies of AA, GG, and AG haplotypes $(p=0.069, p=0.373$, and $p=0.243$, resp.).

\section{Discussion}

Psoriasis is an inflammatory disease which is characterized by keratinocyte proliferation and activated $\mathrm{T}$ cell accumulation [63]. The incidence of psoriasis in women and men is almost equal [3]. However, in our study, the number of female patients (66) was significantly higher than the number of male patients (37). This situation is entirely coincidental and only results from the fact that the number of female patients who applied to the clinic during the study period was more than the number of male patients. Probably, the number of female patients and male patients would be close if the study period was extended a little longer or the number of patients could be increased.

Although its pathogenesis has not been well understood, psoriasis bears many features of a $\mathrm{T}$ cell-mediated autoimmune disease. It reveals a strong HLA association [64]. Since CTLA-4 regulates $\mathrm{T}$ cell activation and the proliferation through a negative feedback, the CTLA-4 gene is considered to be a candidate gene for $\mathrm{T}$ cell-mediated autoimmune disease. Hence, in this study, we aimed to investigate the 
TABLE 4: Genotype and allele frequencies of CTLA-4 gene polymorphisms in the early-onset subgroup and late-onset subgroup and the association of these polymorphisms with onset age of Pv.

\begin{tabular}{|c|c|c|c|c|c|c|c|c|}
\hline SNP & Genotype/allele & Early onset $n(\%)$ & Late onset $n(\%)$ & HWE $p$ (early) & HWE $p$ (late) & Model & OR $(95 \% \mathrm{CI})$ & $p$ \\
\hline rs5742909 & $\mathrm{CC}$ & $74(0.84)$ & $12(0.8)$ & 0.62 & 0.67 & Codominant 1 & $1.42(0.35-5.75)$ & 0.76 \\
\hline \multirow[t]{5}{*}{$(-318 \mathrm{C}>\mathrm{T})$} & $\mathrm{CT}$ & $13(0.15)$ & $3(0.2)$ & & & Codominant 2 & 0.00 (NA) & \\
\hline & $\mathrm{TT}$ & $1(0.01)$ & $0(0.0)$ & & & Dominant & $1.32(0.33-5.30)$ & 0.7 \\
\hline & & & & & & Recessive & $0.00(\mathrm{NA})$ & \\
\hline & $\mathrm{C}$ & $188(0.91)$ & $176(0.86)$ & & & Log-additive & $1.19(0.33-4.30)$ & 0.8 \\
\hline & $\mathrm{T}$ & $18(0.09)$ & $28(0.14)$ & & & Minor allele & $1.19(0.32-4.39)$ & 0.11 \\
\hline rs 231775 & $\mathrm{AA}$ & $45(0.51)$ & $6(0.4)$ & 0.49 & 0.98 & Codominant 1 & $1.54(0.48-5.01)$ & 0.04 \\
\hline \multirow[t]{5}{*}{$(+49 \mathrm{~A}>\mathrm{G})$} & $A G$ & $34(0.39)$ & $7(0.47)$ & & & Codominant 2 & $1.67(0.29-9.62)$ & 0.72 \\
\hline & GG & $9(0.1)$ & $2(0.13)$ & & & Dominant & $1.57(0.52-4.78)$ & 0.42 \\
\hline & & & & & & Recessive & $1.35(0.26-6.97)$ & 0.73 \\
\hline & A & $124(0.7)$ & $19(0.63)$ & & & Log-additive & $1.35(0.62-2.98)$ & 0.45 \\
\hline & G & $52(0.3)$ & $11(0.37)$ & & & Minor allele & $1.38(0.61-3.10)$ & 0.43 \\
\hline rs3087243 & $\mathrm{AA}$ & $24(0.27)$ & $1(0.07)$ & 0.06 & 0.13 & Codominant 1 & $2.07(0.59-7.30)$ & 0.45 \\
\hline \multirow[t]{5}{*}{$(\mathrm{CT} 60 \mathrm{~A}>\mathrm{G})$} & AG & $35(0.4)$ & $10(0.67)$ & & & Codominant 2 & $0.30(0.03-2.89)$ & 0.08 \\
\hline & GG & $29(0.33)$ & $4(0.27)$ & & & Dominant & $1.35(0.40-4.61)$ & 0.62 \\
\hline & & & & & & Recessive & $0.19(0.02-1.53)$ & 0.06 \\
\hline & A & $93(0.53)$ & $18(0.6)$ & & & Log-additive & $0.77(0.36-1.63)$ & 0.49 \\
\hline & G & $83(0.47)$ & $12(0.4)$ & & & Minor allele & $1.34(0.61-2.94)$ & 0.47 \\
\hline
\end{tabular}

SNP: single-nucleotide polymorphism; HWE: Hardy-Weinberg equilibrium; OR: odds ratio; CI: confidence interval.

TABle 5: Genotype and allele frequencies of CTLA-4 gene polymorphisms in PASI $<12$ and PASI $\geq 12$ and the association of these polymorphisms with the severity of $\mathrm{Pv}$.

\begin{tabular}{|c|c|c|c|c|c|c|c|c|}
\hline SNP & Genotype/allele & $\begin{array}{c}\text { PASI < } 12 \\
n(\%)\end{array}$ & $\begin{array}{c}\mathrm{PASI} \geq 12 \\
n(\%)\end{array}$ & $\operatorname{HWE} p(\mathrm{PASI}<12)$ & $\operatorname{HWE} p(\mathrm{PASI} \geq 12)$ & Model & OR $(95 \% \mathrm{CI})$ & $p$ \\
\hline rs5742909 & $\mathrm{CC}$ & $37(0.84)$ & $49(0.83)$ & 0.25 & 0.48 & Codominant 1 & $1.26(0.42-3.78)$ & 0.39 \\
\hline \multirow[t]{5}{*}{$(-318 \mathrm{C}>\mathrm{T})$} & CT & $6(0.14)$ & $10(0.17)$ & & & Codominant 2 & $0.00(\mathrm{NA})$ & \\
\hline & TT & $1(0.02)$ & $0(0.0)$ & & & Dominant & $1.08(0.38-3.10)$ & 0.89 \\
\hline & & & & & & Recessive & $0.00(\mathrm{NA})$ & \\
\hline & $\mathrm{C}$ & $188(0.91)$ & $176(0.86)$ & & & Log-additive & $0.93(0.35-2.43)$ & 0.88 \\
\hline & $\mathrm{T}$ & $18(0.09)$ & $28(0.14)$ & & & Minor allele & $0.93(0.35-2.45)$ & 0.88 \\
\hline rs231775 & $\mathrm{AA}$ & $23(0.52)$ & $28(0.47)$ & 0.84 & 0.36 & Codominant 1 & $1.05(0.46-2.40)$ & 0.04 \\
\hline \multirow[t]{5}{*}{$(+49 A>G)$} & AG & $18(0.41)$ & $23(0.39)$ & & & Codominant 2 & $2.19(0.52-9.22)$ & 0.53 \\
\hline & GG & $3(0.07)$ & $8(0.14)$ & & & Dominant & $1.21(0.55-2.65)$ & 0.63 \\
\hline & & & & & & Recessive & $2.14(0.53-8.60)$ & 0.26 \\
\hline & A & $64(0.73)$ & $79(0.67)$ & & & Log-additive & $1.30(0.72-2.34)$ & 0.39 \\
\hline & G & $24(0.27)$ & $39(0.37)$ & & & Minor allele & $1.32(0.72-2.41)$ & 0.37 \\
\hline rs3087243 & $\overline{\mathrm{AA}}$ & $13(0.3)$ & $12(0.2)$ & 0.79 & 0.23 & Codominant 1 & $0.50(0.19-1.28)$ & 0.08 \\
\hline \multirow[t]{5}{*}{$(\mathrm{CT} 60 \mathrm{~A}>\mathrm{G})$} & $\mathrm{AG}$ & $35(0.4)$ & $24(0.41)$ & & & Codominant 2 & $0.40(0.14-1.18)$ & 0.19 \\
\hline & GG & $10(0.23)$ & $23(0.39)$ & & & Dominant & $0.46(0.19-1.11)$ & 0.08 \\
\hline & & & & & & Recessive & $0.61(0.25-1.51)$ & 0.28 \\
\hline & A & $41(0.47)$ & $70(0.59)$ & & & Log-additive & $0.63(0.37-1.07)$ & 0.09 \\
\hline & G & $47(0.53)$ & $48(0.41)$ & & & Minor allele & $1.67(0.96-2.92)$ & 0.07 \\
\hline
\end{tabular}

SNP: single-nucleotide polymorphism; HWE: Hardy-Weinberg equilibrium; OR: odds ratio; CI: confidence interval.

possibility of an association between this candidate gene and $\mathrm{Pv}$, which is defined as an autoimmune disease. In the present study, $-318 \mathrm{C}>\mathrm{T},+49 \mathrm{~A}>\mathrm{G}$, and CT60 polymorphisms were studied to evaluate their contributions to the pathogenesis of $\mathrm{Pv}$, focusing on their potential effects on the activity and function of the CTLA- 4 molecule. In fact, it has been 
TABLE 6: Haplotype distribution belongs to CTLA-4 polymorphisms between Pv patients and control.

\begin{tabular}{lcccc}
\hline Haplotype & Frequency & $\begin{array}{c}\text { Case/control ratios } \\
\text { (frequency) }\end{array}$ & Chi-square & $p$ \\
\hline CAA & 0.532 & $0.461,0.603$ & 8.274 & $0.004^{\mathrm{a}}$ \\
CGG & 0.253 & $0.306,0.201$ & 5.959 & $0.015^{\mathrm{a}}$ \\
TAG & 0.110 & $0.087,0.132$ & 2.12 & 0.145 \\
CAG & 0.103 & $0.146,0.059$ & 8.379 & $0.004^{\mathrm{a}}$ \\
\hline
\end{tabular}

Haplotypes were constructed in the following order: $-318 \mathrm{C}>\mathrm{T}$ (rs5742909)/ $+49 \mathrm{~A}>\mathrm{G} \quad(\mathrm{rs} 231775) / \mathrm{CT} 60 \mathrm{~A}>\mathrm{G} \quad(\mathrm{rs} 3087243)$. ${ }^{\mathrm{a}}$ Statistically significant values $(p<0.05)$.

suggested that $-318 \mathrm{C}>\mathrm{T}$ polymorphism is an effective promoter activity of the CTLA- 4 gene and change transcription of CTLA-4 gene [65]. $+49 \mathrm{~A}>\mathrm{G}$ polymorphism is located in the leader sequence which is important in the binding of the CTLA-4 molecule to B7.1 (CD80). CT60A>G polymorphism is considered to affect the alternative splicing and soluble CTLA-4 production [66].

Our data displayed no association between $-318 \mathrm{C}>\mathrm{T}$ $\mathrm{SNP}$ and the development of $\mathrm{Pv}$. There were no differences in genotype and allele frequencies between the patient group and the control group. Likewise, Łuszczek et al. [60] found an association between polymorphism and $\mathrm{Pv}$ in their study. It has been also indicated that the association of $-318 \mathrm{C}>\mathrm{T}$ polymorphism with other autoimmune disorders supports our hypothesis. The association of $-318 \mathrm{C}>\mathrm{T}$ polymorphism with other autoimmune diseases such as spondyloarthropathy [67], pemphigus foliaceus [30], multiple sclerosis $[38,68]$, Behçet's disease [35], systemic lupus erythematosus $[37,69]$, Hashimoto's thyroiditis [41, 44], ankylosing spondylitis [40], and Graves' disease [70] supports our findings in which the researchers did not find any significant relationship between $-318 \mathrm{C}>\mathrm{T}$ and other diseases; however, an association between $-318 \mathrm{C}>\mathrm{T}$ polymorphism and other autoimmune disorders was found. The association of $-318 \mathrm{C}>\mathrm{T}$ polymorphism with childhood Graves' disease was reported in a Chinese population [34]. In a study on a Chinese population, a significant relationship was found between $-318 \mathrm{C}>\mathrm{T}$ polymorphism and rheumatoid arthritis $[47,71]$. In the Italian systemic sclerosis patients, an association was found between $-318 \mathrm{C}>\mathrm{T}$ polymorphism and the susceptibility to develop systemic sclerosis [33].

$+49 \mathrm{~A}>\mathrm{G}$ SNP is a CTLA-4 gene polymorphism which is probably the most widely studied and most commonly associated with autoimmune disorders and cancers. In our study, $+49 \mathrm{~A}>\mathrm{G}$ polymorphism indicated a strong relationship with $\mathrm{Pv}$ in terms of minor allele frequency $(\mathrm{OR}=0.59,95 \%$ $\mathrm{CI}=0.38-0.92, p=0.02)$, codominant 1 model $(\mathrm{OR}=1.54$, 95\% $\mathrm{CI}=0.48-5.01 p=0.04)$, dominant genetic model $(\mathrm{OR}=0.54,95 \% \mathrm{CI}=0.40-0.96, p=0.03)$, and log-additive genetic model $(\mathrm{OR}=0.62,95 \% \mathrm{CI}=0.40-0.96, p=0.03)$. In addition, $+49 \mathrm{~A}>\mathrm{G}$ SNP might contribute to the risk of $\mathrm{Pv}$ development and $\mathrm{G}$ allele might be a risk factor in Pv development. This SNP causes substitution of threonine at position 17 to alanine in the CTLA-4 protein [72]. It has been postulated that this amino acid substitution may affect $\mathrm{T}$ cell activation by changing the posttranslational modification and ability of CTLA-4 to bind with B7.1 (CD80) [73]. Various studies have revealed that the $+49 \mathrm{G}$ allele leads to decreased expression of CTLA- 4 compared to $+49 \mathrm{~A}$ allele $[27,74]$. Our findings are probably related to $+49 \mathrm{~A}>\mathrm{G}$ SNP and may be explained by the inability of CTLA- 4 to bind to B7 and/or by decreasing of CTLA-4 expression. Furthermore, decreased expression and/or broken binding with B7 in CTLA-4 may contribute to the pathogenesis of $\mathrm{Pv}$ by changing the $\mathrm{T}$ cell response. The findings of this study are inconsistent with the results of Tsunemi et al. [58], Kim et al. [59], and Łuszczek et al. [61] who evaluated the association between $+49 \mathrm{~A}>\mathrm{G}$ polymorphism and $\mathrm{Pv}$. Luszczek et al. [61] studied on $141 \mathrm{Pv}$ patients recruited from a Polish population and found that the allele and genotype distributions of $+49 \mathrm{~A}>\mathrm{G}$ polymorphism are similar for the patients in the experimental group and healthy individuals in the control group. In the studies with Japanese [58] and Korean [59] populations, no association was reported between polymorphism and $\mathrm{Pv}$. However, the results of some studies examining the relationship of $+49 \mathrm{~A}>\mathrm{G}$ polymorphism with other autoimmune disorder, but not with $\mathrm{Pv}$, are consistent with the results of our study. These studies revealed the association of $+49 \mathrm{~A}>\mathrm{G}$ polymorphism with Graves' disease [27-29, 34, 70], rheumatoid arthritis [39], and ankylosing spondylitis [40]. On the other hand, it has been shown that there is no relation between $+49 \mathrm{~A}>\mathrm{G}$ polymorphism and several autoimmune diseases such as rheumatoid arthritis [43, 71], Behçet's disease [35], vitiligo [75], systemic lupus erythematosus [37, 69], systemic sclerosis [33], spondyloarthropathy [67], ankylosing spondylitis [36, 40], pemphigus foliaceus [30], multiple sclerosis [38, 68], primary Sjögren syndrome [31], and ulcerative colitis [48].

In the present study, we observed a strong association between $\mathrm{CT} 60 \mathrm{~A}>\mathrm{G}$ polymorphism and $\mathrm{Pv}$ in terms of codominant $2(\mathrm{OR}=0.29,95 \% \mathrm{CI}=0.13-0.64, p=0.004)$, recessive $(\mathrm{OR}=1.33,95 \% \mathrm{CI}=0.17-0.60, p=0.001)$, and minor allele frequency $(\mathrm{OR}=0.54,95 \% \mathrm{CI}=0.37-0.80$, $p=0.002$ ). Allele $\mathrm{G}$ appears to be a risk factor for the development of Pv. Łuszczek et al. [61] observed no difference in allele and genotype distributions of CT60A $>\mathrm{G}$ polymorphism between Pv patients and control subjects. This SNP is located in $3^{\prime}$ UTR (untranslated region) of the CTLA-4 gene and is supposed to affect the proportion of soluble isoform of CTLA-4 (sCTLA-4) to membrane-bound CTLA-4 (mCTLA-4). sCTLA-4 isoform is generated through alternative splicing of CTLA- 4 mRNA. It has been previously suggested that the $G$ allele on position +6230 (CT60G) may decrease sCTLA-4 transcript up to 50\% [66]. Furthermore, we also observed higher frequencies of $\mathrm{G}$ allele and GG genotype in Pv patients than the control group. It is assumed G allele causes a decrease in CTLA- 4 expression and deterioration of the balance between sCTLA-4/mCTLA- 4 by blocking the alternative splicing of CTLA-4 mRNA. Chong et al. [34] have suggested that $\mathrm{CT} 60 \mathrm{~A}>\mathrm{G}$ polymorphism plays a role in susceptibility to childhood Graves' disease. Kavvoura et al. [32] have discovered that polymorphism can be an important marker of genetic risk in Graves' disease and Hashimoto thyroiditis. Furthermore, it has also been suggested that 
TABLE 7: Haplotype distribution belongs to CTLA-4 polymorphisms among different subgroups of Pv.

(a)

\begin{tabular}{lcccr}
\hline Haplotype & Frequency & Late/early ratios (frequency) & Chi-square & $p$ \\
\hline AA & 0.461 & $0.472,0.400$ & 0.529 & 0.467 \\
GG & 0.306 & $0.295,0.367$ & 0.612 & 0.434 \\
AG & 0.233 & $0.233,0.263$ & 1.364 & 0.243 \\
\hline
\end{tabular}

(b)

\begin{tabular}{lccr}
\hline Haplotype & Frequency & $\begin{array}{c}\text { PASI }<12 / \text { PASI } \geq 12 \text { ratios } \\
\text { (frequency) }\end{array}$ & Chi-square \\
\hline AA & 0.461 & $0.534,0.407$ & 3.288 \\
GG & 0.306 & $0.273,0.331$ & 0.793 \\
AG & 0.233 & $0.193,0.263$ & 0.069 \\
\hline
\end{tabular}

Haplotypes were constructed in the following order: $+49 \mathrm{~A}>\mathrm{G}(\mathrm{rs} 231775) / \mathrm{CT} 60 \mathrm{~A}>\mathrm{G}(\mathrm{rs} 3087243)$.

CT60A $>$ G polymorphism leads to the susceptibility of vitiligo [75] and ankylosing spondylitis [40].

There are several reasons that could explain these controversial results among different studies: (i) studied populations have different ethnic features, (ii) studied populations have different sizes, and (iii) studied autoimmune disorders have already a multifactorial nature. In this study, $-318 \mathrm{C}>\mathrm{T},+49 \mathrm{~A}>\mathrm{G}$, and $\mathrm{CT} 60 \mathrm{~A}>\mathrm{G}$ polymorphisms were selected because they can play a role on $\mathrm{Pv}$ pathogenesis by altering the promoter activity and transcription efficiency (for $-318 \mathrm{C}>\mathrm{T}$ ), by altering $\mathrm{T}$ cell activation through posttranslational modification (for $+49 \mathrm{~A}>\mathrm{G}$ ), and by affecting the alternative splicing and production of CTLA-4 isoforms (for CT60A>G). Although our population size was relatively small, we believe that our results will contribute to metaanalysis studies which have aimed at understanding the role of CTLA-4 on the pathogenesis of Pv.

\section{Conclusions}

To conclude, our data suggest that while there seems to be no correlation between $-318 \mathrm{C}>\mathrm{T}$ polymorphism and the development of $\mathrm{Pv},+49 \mathrm{~A}>\mathrm{G}$ and $\mathrm{CT} 60 \mathrm{~A}>\mathrm{G}$ polymorphisms may be associated with the development of Pv. In addition, our results present that none of the studied polymorphisms were related with the clinical features of $\mathrm{Pv}$ such as severity and onset age of disease. In performed haplotype analysis, CGG and CAG haplotypes were found to be the risk factor for the development of $\mathrm{Pv}$, while CAA haplotype was found to be a protective haplotype for $\mathrm{Pv}$. The haplotypes showed no association with severity and onset age of $\mathrm{Pv}$. As a result, all of these findings suggest that $+49 \mathrm{~A}>\mathrm{G}$ and $\mathrm{CT} 60 \mathrm{~A}>\mathrm{G}$ polymorphisms of the CTLA-4 gene may play a role in the pathogenesis of $\mathrm{Pv}$.

\section{Conflicts of Interest}

The authors declare that there are no conflicts of interest regarding the publication of this article.

\section{Acknowledgments}

This study was supported by Grant no. 10202049 from the Scientific Research Project Unit of Selçuk University.

\section{References}

[1] International Federation of Psoriasis Associations, "World psoriasis day 2015," February 2018, https://ifpa-pso.com/ouractions/world-psoriasis-day.

[2] R. B. G. Langley, G. G. Krueger, and C. E. M. Griffiths, "Psoriasis: epidemiology, clinical features, and quality of life," Annals of the Rheumatic Diseases, vol. 64, Supplement 2, pp. iil8ii23, 2005.

[3] C. E. M. Griffiths and J. N. W. N. Barker, "Pathogenesis and clinical features of psoriasis," The Lancet, vol. 370, no. 9583, pp. 263-271, 2007.

[4] J. E. Gudjonsson and J. T. Elder, "Psoriasis: epidemiology," Clinics in Dermatology, vol. 25, no. 6, pp. 535-546, 2007.

[5] A. J. Hueber and I. B. McInnes, "Immune regulation in psoriasis and psoriatic arthritis-recent developments," Immunology Letters, vol. 114, no. 2, pp. 59-65, 2007.

[6] D. J. Najarian and A. B. Gottlieb, "Connections between psoriasis and Crohn's disease," Journal of the American Academy of Dermatology, vol. 48, no. 6, pp. 805-824, 2003.

[7] A. B. Kimball, D. Gladman, J. M. Gelfand et al., "National Psoriasis Foundation clinical consensus on psoriasis comorbidities and recommendations for screening," Journal of the American Academy of Dermatology, vol. 58, no. 6, pp. 10311042, 2008.

[8] S. C.-H. Hu and C.-C. E. Lan, "Psoriasis and cardiovascular comorbidities: focusing on severe vascular events, cardiovascular risk factors and implications for treatment," International Journal of Molecular Sciences, vol. 18, no. 12, p. 2211, 2017.

[9] R. A. Kölliker Frers, R. J. Bisoendial, S. F. Montoya et al., "Psoriasis and cardiovascular risk: immune-mediated crosstalk between metabolic, vascular and autoimmune inflammation," IJC Metabolic \& Endocrine, vol. 6, pp. 43-54, 2015.

[10] A. Parodi, N. Aste, C. Calvieri et al., "Metabolic syndrome prevalence in psoriasis: a cross-sectional study in the Italian 
population," American Journal of Clinical Dermatology, vol. 15, no. 4, pp. 371-377, 2014.

[11] I. M. Miller, C. Ellervik, K. Zarchi et al., "The association of metabolic syndrome and psoriasis: a population- and hospital-based cross-sectional study," Journal of the European Academy of Dermatology and Venereology, vol. 29, no. 3, pp. 490-497, 2015.

[12] A. S. Lonnberg, L. Skov, A. Skytthe, K. O. Kyvik, O. B. Pedersen, and S. F. Thomsen, "Association of psoriasis with the risk for type 2 diabetes mellitus and obesity," JAMA Dermatology, vol. 152, no. 7, pp. 761-767, 2016.

[13] E. A. Dowlatshahi, M. Wakkee, L. R. Arends, and T. Nijsten, "The prevalence and odds of depressive symptoms and clinical depression in psoriasis patients: a systematic review and metaanalysis," Journal of Investigative Dermatology, vol. 134, no. 6, pp. 1542-1551, 2014.

[14] K. Abuabara, R. S. Azfar, D. B. Shin, A. L. Neimann, A. B. Troxel, and J. M. Gelfand, "Cause-specific mortality in patients with severe psoriasis: a population-based cohort study in the U.K," British Journal of Dermatology, vol. 163, no. 3, pp. 586-592, 2010.

[15] J. M. Gelfand, J. Berlin, A. Van Voorhees, and D. J. Margolis, "Lymphoma rates are low but increased in patients with psoriasis: results from a populationbased study in the United Kingdom," Archives of Dermatology, vol. 139, no. 11, pp. 1425-1429, 2003.

[16] C. Ryan and B. Kirby, "Psoriasis is a systemic disease with multiple cardiovascular and metabolic comorbidities," Dermatologic Clinics, vol. 33, no. 1, pp. 41-55, 2015.

[17] R. Parisi, D. P. Symmons, C. E. Griffiths, D. M. Ashcroft, and Identification and Management of Psoriasis and Associated ComorbidiTy (IMPACT) project team, "Global epidemiology of psoriasis: a systematic review of incidence and prevalence," Journal of Investigative Dermatology, vol. 133, no. 2, pp. 377-385, 2013.

[18] M. P. Schön and W.-H. Boehncke, "Psoriasis," The New England Journal of Medicine, vol. 352, no. 18, pp. 1899-1912, 2005.

[19] M. A. Lowes, A. M. Bowcock, and J. G. Krueger, "Pathogenesis and therapy of psoriasis," Nature, vol. 445, no. 7130, pp. 866-873, 2007.

[20] L. Naldi and D. Gambini, "The clinical spectrum of psoriasis," Clinics in Dermatology, vol. 25, no. 6, pp. 510-518, 2007.

[21] S. K. Raychaudhuri, E. Maverakis, and S. P. Raychaudhuri, "Diagnosis and classification of psoriasis," Autoimmunity Reviews, vol. 13, no. 4-5, pp. 490-495, 2014.

[22] C. B. Thompson and J. P. Allison, "The emerging role of CTLA-4 as an immune attenuator," Immunity, vol. 7 , no. 4 , pp. 445-450, 1997.

[23] A. G. Baxter and P. D. Hodgkin, "Activation rules: the twosignal theories of immune activation," Nature Reviews Immunology, vol. 2, no. 6, pp. 439-446, 2002.

[24] M. L. Alegre, K. A. Frauwirth, and C. B. Thompson, "T-cell regulation by CD28 and CTLA-4," Nature Reviews Immunology, vol. 1, no. 3, pp. 220-228, 2001.

[25] D. M. Harlan, R. Abe, K. P. Lee, and C. H. June, "Potential roles of the $\mathrm{B} 7$ and $\mathrm{CD} 28$ receptor families in autoimmunity and immune evasion," Clinical Immunology and Immunopathology, vol. 75, no. 2, pp. 99-111, 1995.

[26] M. Lafage-Pochitaloff, R. Costello, D. Couez et al., "Human CD28 and CTLA-4 Ig superfamily genes are located on chromosome 2 at bands q33-q34," Immunogenetics, vol. 31, no. 3, pp. 198-201, 1990.

[27] T. Kouki, Y. Sawai, C. A. Gardine, M.-E. Fisfalen, M.-L. Alegre, and L. J. DeGroot, "CTLA-4 gene polymorphism at position 49 in exon I reduces the inhibitory function of CTLA-4 and contributes to the pathogenesis of Graves' disease," The Journal of Immunology, vol. 165, no. 11, pp. 6606-6611, 2000.

[28] T. Yanagawa, M. Taniyama, S. Enomoto et al., "CTLA4 gene polymorphism confers susceptibility to Graves' disease in Japanese," Thyroid, vol. 7, no. 6, pp. 843-846, 1997.

[29] T. Bednarczuk, Y. Hiromatsu, T. Fukutani et al., "Association of cytotoxic T-lymphocyte-associated antigen-4 (CTLA-4) gene polymorphism and non-genetic factors with Graves' ophthalmopathy in European and Japanese populations," European Journal of Endocrinology, vol. 148, no. 1, pp. 13-18, 2003.

[30] D. P. Pavoni, L. B. Cerqueira, V. M. M. S. Roxo, and M. L. Petzl-Erler, "Polymorphism of the promoter region and exon 1 of the CTLA4 gene in endemic pemphigus foliaceus (fogo selvagem)," Brazilian Journal of Medical and Biological Research, vol. 39, no. 9, pp. 1227-1232, 2006.

[31] J. E. Gottenberg, P. Loiseau, M. Azarian et al., "CTLA-4 +49A/ $\mathrm{G}$ and CT60 gene polymorphisms in primary Sjögren syndrome," Arthritis Research \& Therapy, vol. 9, no. 2, p. R24, 2007.

[32] F. K. Kavvoura, T. Akamizu, T. Awata et al., "Cytotoxic Tlymphocyte associated antigen 4 gene polymorphisms and autoimmune thyroid disease: a meta-analysis," The Journal of Clinical Endocrinology \& Metabolism, vol. 92, no. 8, pp. 3162-3170, 2007, Review.

[33] G. Balbi, F. Ferrera, M. Rizzi et al., "Association of $-318 \mathrm{C} / \mathrm{T}$ and $+49 \mathrm{~A} / \mathrm{G}$ cytotoxic T lymphocyte antige4 (CTLA-4) gene polymorphisms with a clinical subset of Italian patients with systemic sclerosis," Clinical \& Experimental Immunology, vol. 149, no. 1, pp. 40-47, 2007.

[34] K. K. L. Chong, S. W. Y. Chiang, G. W. K. Wong et al., “Association of CTLA-4 and IL-13 gene polymorphisms with Graves' disease and ophthalmopathy in Chinese children," Investigative Ophthalmology \& Visual Science, vol. 49, no. 6, pp. 2409-2415, 2008.

[35] L. Du, P. Yang, S. Hou, H. Zhou, and A. Kijlstra, "No association of CTLA-4 polymorphisms with susceptibility to Behçet disease," British Journal of Ophthalmology, vol. 93, no. 10, pp. 1378-1381, 2009.

[36] E. Azizi, A. Massoud, A. A. Amirzargar et al., "Association of $C T L A_{4}$ gene polymorphism in Iranian patients with ankylosing spondylitis," Journal of Clinical Immunology, vol. 30, no. 2, pp. 268-271, 2010.

[37] K. H. Chua, S. M. Puah, C. H. Chew, S. Y. Tan, and L. H. Lian, "Study of the CTLA-4 gene polymorphisms in systemic lupus erythematosus (SLE) samples from Malaysia," Annals of Human Biology, vol. 37, no. 2, pp. 274-280, 2010.

[38] A. Heidari, M. Keramatipour, A. A. Amirzargar et al., "CTLA4 gene polymorphisms $(-318 \mathrm{C} / \mathrm{T},+49 \mathrm{~A} / \mathrm{G},+6230 \mathrm{~A} / \mathrm{G})$ in Iranian patients with multiple sclerosis," Iranian Journal of Allergy Asthma and Immunology, vol. 9, no. 4, article 21131701, pp. 219-223, 2010.

[39] M. J. Tang and Z. B. Zhou, "Association of the CTLA-4 +49A/ G polymorphism with rheumatoid arthritis in Chinese Han population," Molecular Biology Reports, vol. 40, no. 3, pp. 2627-2631, 2013. 
[40] N. G. Wang, D. C. Wang, B. Y. Tan, F. Wang, and Z. N. Yuan, "Association between CTLA-4 gene polymorphism and ankylosing spondylitis: a case-control study," International Journal of Clinical and Experimental Pathology, vol. 8, no. 6, pp. 7421-7425, 2015.

[41] Y. Hu, K. Xu, L. Jiang, L. Zhang, H. Shi, and D. Cui, “Associations between three CTLA-4 polymorphisms and Hashimoto's thyroiditis risk: an updated meta-analysis with trial sequential analysis," Genetic Testing and Molecular Biomarkers, vol. 22, no. 4, pp. 1-13, 2018.

[42] S. Ramgopal, C. Rathika, M. R. Padma et al., "Interaction of HLA-DRB $1 *$ alleles and CTLA4 (+ 49 AG) gene polymorphism in autoimmune thyroid disease," vol. 642, pp. 430-438, 2018.

[43] K. Wang, Q. Zhu, Y. Lu et al., "CTLA-4 +49 G/A polymorphism confers autoimmune disease risk: an updated metaanalysis," Genetic Testing and Molecular Biomarkers, vol. 21, no. 4, pp. 222-227, 2017.

[44] W. H. Ting, M. N. Chien, F. S. Lo et al., "Association of cytotoxic T-lymphocyte-associated protein 4 (CTLA4) gene polymorphisms with autoimmune thyroid disease in children and adults: case-control study," PLoS One, vol. 11, no. 4, article e0154394, 2016.

[45] H. Patel, M. S. Mansuri, M. Singh, R. Begum, M. Shastri, and A. Misra, "Association of cytotoxic T-lymphocyte antigen 4 (CTLA4) and thyroglobulin (TG) genetic variants with autoimmune hypothyroidism," PLoS One, vol. 11, no. 3, article e0149441, 2016.

[46] K. Luterek-Puszyńska, D. Malinowski, A. ParadowskaGorycka, K. Safranow, and A. Pawlik, "CD28, CTLAand $\mathrm{CCL}_{5}$ gene polymorphisms in patients with rheumatoid arthritis," Clinical Rheumatology, vol. 36, no. 5, pp. 1129-1135, 2017.

[47] S. A. Fattah, M. H. Ghattas, S. M. Saleh, and D. M. Abo-Elmatty, "Cytotoxic T-lymphocyte-associated protein 4 gene polymorphism is related to rheumatoid arthritis in Egyptian population," Archives of Physiology and Biochemistry, vol. 123, no. 1, pp. 50-53, 2017.

[48] J. J. Zhao, D. Wang, H. Yao, D. W. Sun, and H. Y. Li, “CTLA-4 and MDR1 polymorphisms increase the risk for ulcerative colitis: a meta-analysis," World Journal of Gastroenterology, vol. 21, no. 34, pp. 10025-10040, 2015.

[49] J. Zhou, D. Sun, L. Xu, L. Sun, S. Fu, and Y. Li, “ADAM33 as a psoriasis susceptibility gene in the Han population of Northeastern China," Dermatology, vol. 223, no. 4, pp. 356-362, 2011.

[50] G. Shi, T. Wang, S. Li et al., "TLR2 and TLR4 polymorphisms in Southern Chinese psoriasis vulgaris patients," Journal of Dermatological Science, vol. 83, no. 2, pp. 145-147, 2016.

[51] M. Zablotna, M. Sobjanek, D. Purzycka-Bohdan, A. Szczerkowska-Dobosz, B. Nedoszytko, and R. Nowicki, "The -2518 A/G MCP-1 and -403 G/A RANTES promoter gene polymorphisms are associated with psoriasis vulgaris," Clinical and Experimental Dermatology, vol. 41, no. 8, pp. 878-883, 2016.

[52] D. Rajesh, R. Gurumurthy, A. V. Kutt, and S. Balakrishna, "Tumor necrosis factor alpha gene promoter -238G/A polymorphism increases the risk of psoriasis vulgaris in Indian patients," International Journal of Dermatology, vol. 56, no. 3, pp. 307-311, 2017.
[53] G. Kalkan, H. Y. Seçkin, I. Benli et al., "Association of paraoxonase 1 (PON1) L55M and PON1 Q192R gene polymorphisms and risk of psoriasis," Giornale Italiano di Dermatologia e Venereologia, vol. 11, 2017.

[54] S. Indhumathi, M. Rajappa, L. Chandrashekar, P. H. Ananthanarayanan, D. M. Thappa, and V. S. Negi, "T helper2 cytokine/regulatory T-cell gene polymorphisms and their relation with risk of psoriasis in a South Indian Tamil cohort," Human Immunology, vol. 78, no. 2, pp. 209-215, 2017.

[55] J. Hirata, T. Hirota, T. Ozeki et al., "Variants at HLA-A, $H L A-C$, and $H L A-D Q B 1$ confer risk of psoriasis vulgaris in Japanese," Journal of Investigative Dermatology, vol. 138, no. 3, pp. 542-548, 2018.

[56] A. Sudhesan, M. Rajappa, L. Chandrashekar et al., "Vascular endothelial growth factor (VEGF) gene polymorphisms (rs699947, rs833061, and rs2010963) and psoriatic risk in South Indian Tamils," Human Immunology, vol. 78, no. 10, pp. 657-663, 2017.

[57] A. Wiśniewski, Ł. Matusiak, A. Szczerkowska-Dobosz, I. Nowak, W. Łuszczek, and P. Kuśnierczyk, "The association of ERAP1 and ERAP2 single nucleotide polymorphisms and their haplotypes with psoriasis vulgaris is dependent on the presence or absence of the $H L A-C^{*} 06: 02$ allele and age at disease onset," Human Immunology, vol. 79, no. 2, pp. 109-116, 2018.

[58] Y. Tsunemi, H. Saeki, M. Kishimoto et al., "Cytotoxic T lymphocyte antigen-4 gene (CTLA4) polymorphisms in Japanese patients with psoriasis vulgaris," Journal of Dermatological Science, vol. 32, no. 2, pp. 163-165, 2003.

[59] Y. K. Kim, C. W. Pyo, S. S. Hur, T. Y. Kim, and T. G. Kim, "No associations of CTLA-4 and ICAM-1 polymorphisms with psoriasis in the Korean population," Journal of Dermatological Science, vol. 33, no. 1, pp. 75-77, 2003.

[60] W. Łuszczek, W. Kubicka, M. Jasek et al., "CTLA-4 gene polymorphisms and natural soluble CTLA-4 protein in psoriasis vulgaris," International Journal of Immunogenetics, vol. 33, no. 3, pp. 217-224, 2006.

[61] W. Łuszczek, E. Majorczyk, P. Nockowski et al., "Distribution of the CTLA-4 single nucleotide polymorphisms CT60G $>$ A and $+49 \mathrm{~A}>\mathrm{G}$ in psoriasis vulgaris patients and control individuals from a Polish Caucasian population," International Journal of Immunogenetics, vol. 35, no. 1, pp. 51-55, 2008.

[62] T. Fredriksson and U. Pettersson, "Severe psoriasis - oral therapy with a new retinoid," Dermatologica, vol. 157 , no. 4 , pp. 238-244, 1978.

[63] P. J. Mease and A. W. Armstrong, "Managing patients with psoriatic disease: the diagnosis and pharmacologic treatment of psoriatic arthritis in patients with psoriasis," Drugs, vol. 74, no. 4, pp. 423-441, 2014.

[64] F. Zhou, H. Cao, X. Zuo et al., "Deep sequencing of the MHC region in the Chinese population contributes to studies of complex disease," Nature Genetics, vol. 48, no. 7, pp. 740-746, 2016.

[65] X. P. Wang, X. Zhao, R. Giscombe, and A. K. Lefvert, "A CTLA-4 gene polymorphism at position -318 in the promoter region affects the expression of protein," Genes \& Immunity, vol. 3, no. 4, pp. 233-234, 2002.

[66] H. Ueda, J. M. M. Howson, L. Esposito et al., "Association of the T-cell regulatory gene CTLA4 with susceptibility to autoimmune disease," Nature, vol. 423, no. 6939, pp. 506-511, 2003. 
[67] Y. H. Lee, J. D. Ji, J. Sohn, and G. G. Song, "Polymorhisms of CTLA-4 exon I +49, CTLA-4 promoter -318 and Fas promoter -670 in spondyloarthropathies," Clinical Rheumatology, vol. 20, no. 6, pp. 420-422, 2001.

[68] T. Fukazawa, S. Kikuchi, R. Miyagishi et al., "CTLA-4 gene polymorphism is not associated with conventional multiple sclerosis in Japanese," Journal of Neuroimmunology, vol. 159, no. 1-2, pp. 225-229, 2005.

[69] L. L. Hudson, K. Rocca, Y. W. Song, and J. P. Pandey, "CTLA-4 gene polymorphisms in systemic lupus erythematosus: a highly significant association with a determinant in the promoter region," Human Genetics, vol. 111, no. 4-5, pp. 452-455, 2002.

[70] A. Esteghamati, O. Khalilzadeh, Z. Mobarra et al., "Association of CTLA-4 gene polymorphism with Graves' disease and ophthalmopathy in Iranian patients," European Journal of Internal Medicine, vol. 20, no. 4, pp. 424-428, 2009.

[71] C. P. Liu, J. A. Jiang, T. Wang et al., "CTLA-4 and CD86 genetic variants and haplotypes in patients with rheumatoid arthritis in southeastern China," Genetics and Molecular Research, vol. 12, no. 2, pp. 1373-1382, 2013.

[72] K. Harper, C. Balzano, E. Rouvier, M. G. Mattéi, M. F. Luciani, and P. Golstein, "CTLA-4 and CD28 activated lymphocyte molecules are closely related in both mouse and human as to sequence, message expression, gene structure, and chromosomal location," The Journal of Immunology, vol. 147, no. 3, pp. 1037-1044, 1991.

[73] T. Sun, Y. Zhou, M. Yang et al., "Functional genetic variations in cytotoxic T-lymphocyte antigen 4 and susceptibility to multiple types of cancer," Cancer Research, vol. 68, no. 17, pp. 7025-7034, 2008.

[74] M. Mäurer, S. Loserth, A. Kolb-Mäurer et al., "A polymorphism in the human cytotoxic T-lymphocyte antigen 4 (CTLA4) gene (exon $1+49$ ) alters T-cell activation," Immunogenetics, vol. 54, no. 1, pp. 1-8, 2002.

[75] G. G. Song, J. H. Kim, and Y. H. Lee, "The CTLA-4 +49 A/G, CT60 A/G and PTPN22 $1858 \mathrm{C} / \mathrm{T}$ polymorphisms and susceptibility to vitiligo: a meta-analysis," Molecular Biology Reports, vol. 40, no. 4, pp. 2985-2993, 2013. 


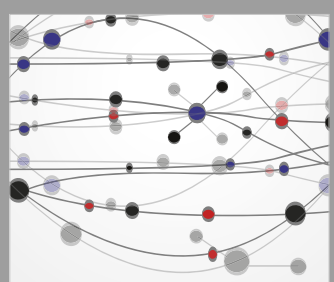

The Scientific World Journal
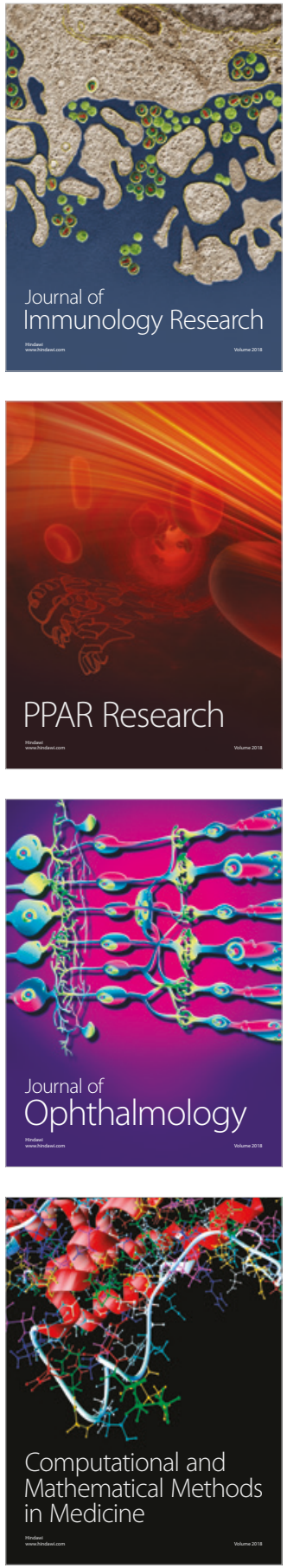

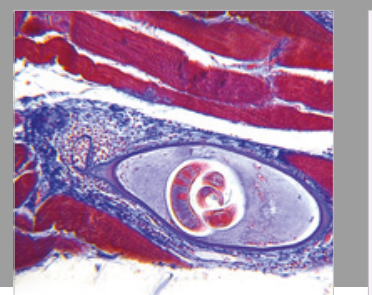

Gastroenterology Research and Practice

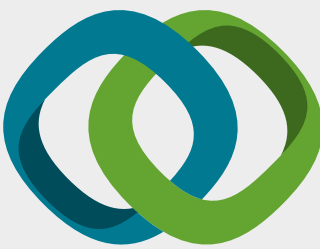

\section{Hindawi}

Submit your manuscripts at

www.hindawi.com
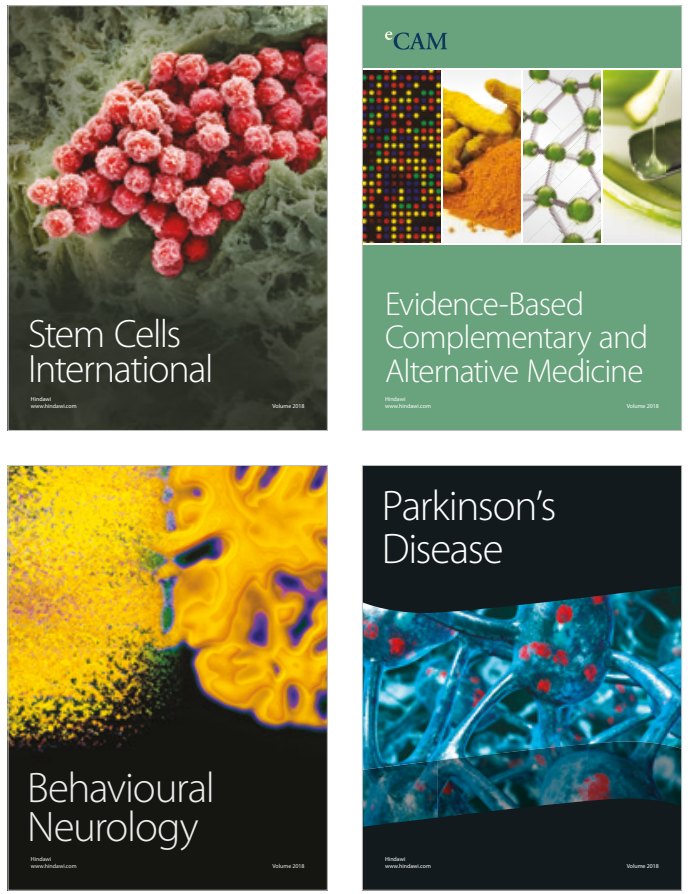

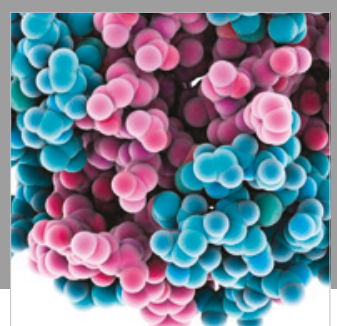

ournal of

Diabetes Research

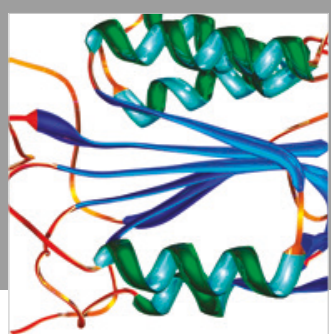

Disease Markers
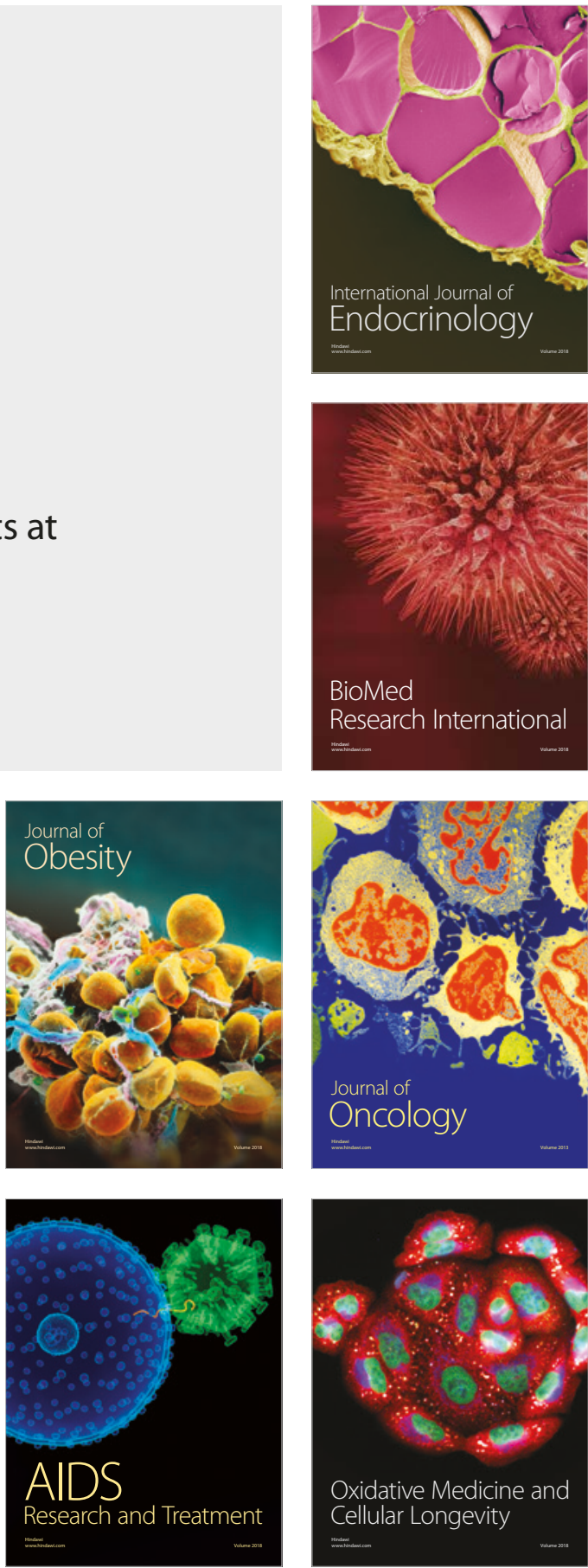